\title{
LOCAL TEXTURES IN DEFORMED AND RECRYSTALLIZED ALUMINIUM CRYSTALS
}

\author{
A. AKEF and J. H. DRIVER \\ Materials Department, Ecole des Mines de Saint-Etienne, 158, Cours Fauriel, \\ 42023 Saint-Etienne Cedex 2, France
}

The recrystallization mechanisms in deformed aluminium single crystals have been investigated by SEM microdiffraction techniques (ECP and EBSP). Aluminium crystals of $(001)\langle u v 0\rangle$ and (001)[011] orientations were deformed in plane strain compression to a true strain of $\sim 1$ to develop different deformation microstructures. Transition bands separating deformation bands were formed by orientation splitting in the $(001)\langle u v 0\rangle$ crystals, but were not observed in the (001)[011] crystal.

During annealing at $250^{\circ} \mathrm{C}$ and $400^{\circ} \mathrm{C}$, recrystallization nuclei are developed in both the deformed matrix and along transition bands. Matrix nucleation appears to occur by a subgrain coalescence mechanism according to which the new grains are misoriented $15-30^{\circ}$ from the average as-deformed material. Transition band nucleation gives an orientation spread $20-30^{\circ}$ around the original, undeformed crystal orientation. A well-defined cube recrystallization texture is obtained at $400^{\circ} \mathrm{C}$ after complete recrystallization of the initial cube crystal.

KEY WORDS Recrystallization, aluminium, single crystals, microtextures, nucleation.

\section{INTRODUCTION}

The basic mechanisms controlling the grain orientations developed by recrystallization from a deformed matrix have been at the centre of scientific controversy for a long time-see for example the panel review of ICOTOM 8 (Doherty et al., 1988). In particular, an objective assessment of the relative merits of the oriented nucleation and oriented growth theories requires critical experiments that have been difficult to perform. There are two crucial experimental difficulties which have limited development in this field. First, and quite obviously, most previous studies have used macroscopic techniques, e.g. $\mathrm{X}$-ray pole figures, for determining average grain orientations during recrystallization although the latter is controlled by microscopic processes. The advent of the new SEM microtexture techniques such as ECP and EBSP, combining good spatial resolution with rapid orientation analysis, will clearly overcome this difficulty. Recent studies using EBSP on rolled and partially recrystallized aluminium alloys (Hjelen, Orsund and Nes, 1991) have shed new light on the orientation relations between recrystallization nuclei and the adjacent deformed grains.

A second, more subtle, problem concerns the heterogeneous nature of the deformation microstructures of most heavily deformed polycrystalline alloys. Deformation heterogeneities occur between grains, around 2nd phase particles and within grains in the form of deformation bands, transition bands and shear 
bands. Each of these microstructural features has a specific influence on recrystallization which needs to be understood, in particular much work remains to be done concerning the role of deformation and transition bands.

The latter are often considered to be nucleation sites because of their high lattice orientation gradients. In fcc metals they are often thought to be the nucleation sites for cube grains, (Dillamore and Katoh, 1974; Hjelen, Orsund and Nes, 1991), - a version of the oriented nucleation theory of the cube recrystallization texture.

Recent plane strain compression experiments on suitably oriented $\mathrm{Al}$ single crystals (Akef and Driver, 1991; Becker et al., 1991) have shown that transition bands, situated between strongly misoriented deformation bands, can be formed in a reproducible way. Crystals with the cube [001] direction parallel to the compression axis split up during plane strain compression to develop transition bands in the RD/TD plane and/or the RD/ND plane. This opens up the possibility of studying, in a systematic way, the nucleation mechanisms of recrystallization from transition bands.

The present paper describes on-going research aimed at clarifying the recrystallization mechanisms in deformation substructures characterized by high lattice orientation gradients. The grain nucleation sites and the subsequent recrystallization process have been studied by local microtexture measurements and the results discussed in terms of the theories of oriented nucleation and growth.

\section{EXPERIMENTAL}

High purity $(99,996 \%)$ aluminium single crystals were obtained by controlled horizontal solidification. The $10 \times 5 \times 5 \mathrm{~mm}$ compression samples were machined from the large single crystals using a water cooled cutting disc. Before testing the crystal samples were electropolished and their orientations determined by the back-reflexion Laue X-ray method. The orientations used in this study were (001)[010], (001)[110], (001)[250] and (011)[011] .

The crystals were deformed in plane strain compression using a channel die arrangement with Teflon lubrication. The experimental details have been described by Skalli (1984) and Orlans-Joliet, Driver and Montheillet (1990). Slip lines were observed by standard optical microscopy. After deformation crystal orientations were determined by pole figures using a fully automated X-ray goniometer.

After true stains of the order of 1 or 1.5 the crystals were annealed for different times at temperatures of 120,250 and $400^{\circ} \mathrm{C}$ to different microstructural states; recovery, partial and complete recrystallization. Local orientations were determined by both SACP (Selected area channelling patterns) and EBSP (Electron Back Scattered Patterns) using a JEOL JSM 6400 SEM. The EBSP equipments is virtually the same as that described by Hjelen, Orsund and Nes (1991). For both the ECP and EBSP techniques, grain orientations were determined on-line using the Channel software described by Schmidt and Olesen (1989). 


\section{DEFORMATION BEHAVIOUR}

Plane strain compression of cube oriented crystals $(001)\langle u v 0\rangle$ leads to the development of deformation bands by lattice rotations of opposite sign about the transverse direction, TD. The details of this orientation splitting have been described by Akef and Driver (1991) for the (001)[010] and $(001)\langle 110\rangle$ orientations and also by Becker et al. (1991) for the latter case. The essential features of the process, as recalled below, are presented schematically in Figure 1.

(i) up to a critical strain $\varepsilon_{c}$ of the order of 0.2 to 0.3 the deformation is relatively homogeneous, i.e. the slip lines visible by optical microscopy are distributed homogeneously and the X-ray figures indicate little orientation spread.

(ii) Above this critical strain the crystals separate into regions characterized by lattice rotations of opposite sign about the transverse axis. The different crystal orientations examined here decompose as follows:

-(001)[010](cube)

at a strain of 1 to 1.5 , deformation bands with two complementary orientations (049) $[09 \overline{4}]+(0 \overline{4} 9)[094]$ are developed, separated by transition bands stacked in the RD/ND plane (Figure 1a).

- (001)[110] $\left(45^{\circ} \mathrm{ND}\right.$ rotated cube)

at a strain of 1.2 deformation bands composed of 2 " $\mathrm{Cu}$ " type orientations $(112)[11 \overline{1}]+(\overline{1} \overline{1} 2)[111]$ are formed with transition bands stacked in the RD/TD plane of the sample thickness.

- $(001)\langle 250\rangle\left(22^{\circ}\right.$ ND rotated cube $)$

in this case deformation bands are generated both in the RD/TD and the $\mathrm{RD} / \mathrm{ND}$ planes with, at $\varepsilon \sim 0.9$ approximate orientations $(2,5,10)\langle\overline{2} \overline{5} 3\rangle$ and $(\overline{2} \overline{5} 10)\langle 253\rangle$. An example of the orientation splitting at $\varepsilon=0,5$ is shown in Figure 2 .

Note that, with the exception of the $(112)\langle 111\rangle$ components obtained in the (001)[110] crystal, the deformation band orientations at $\varepsilon=1$ are unstable and decompose toward "S" type $\{123\}\langle 412\rangle$ orientations on further rolling to a strain of 3 .

In all cases the deformation bands are relatively wide regions (on a scale of 10 to $100 \mu \mathrm{m}$ ) of single or double slip separated by narrow transition bands (width $1-3 \mu \mathrm{m}$ ) where most of the lattice misorientation is concentrated. The transition bands are thought to have orientations close to the original crystal orientation.

The lattice rotations of opposite sign about the transverse direction are predicted quite accurately by a simple analytical model of localized band deformation in which the normal strain components are taken equal to the macroscopic values and the shear strain components are considered unconstrained.

The (011)[011] crystal is significantly harder than the $(001)\langle$ uv 0$\rangle$ crystals in accordance with the Taylor factors which differ by a factor of 2 ( $2 \sqrt{6}$ compared with $\sqrt{6}$ for the cube crystals). It also deforms quite differently. At the optical 
Fig. 1a : Cube (001) [010]

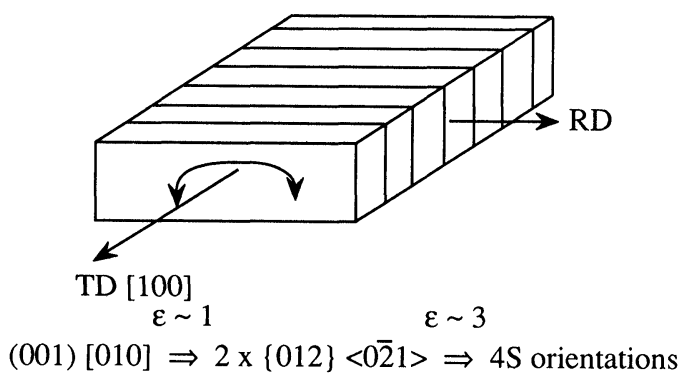

Fig. $1 \mathrm{~b}: 45^{\circ} \mathrm{ND}$ rotated cube $(001)[110]$

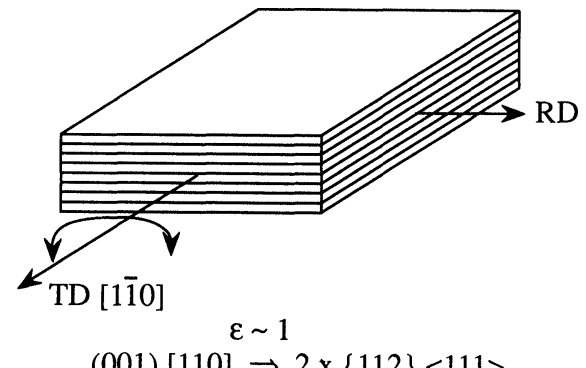

Fig. 1c : $22^{\circ} \mathrm{ND}$ rotated cube (001) [250]

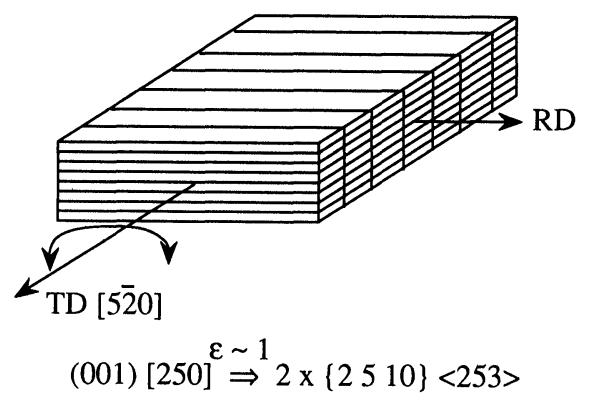

Figure 1 Schematic illustrations of orientation splitting in (001) $\langle$ uv0 $\rangle$ crystals; (a) (001)[010), (b) $(001)[110]$ and (c) (001)[250].

microscopy level deformation appears to be distributed homogeneously throughout the sample for strains up to $\sim 1$. However, X-ray pole figures at this stage (Figure 3 ) reveal a very wide orientation spread towards a near-fibre texture. Here again the lattice rotations occur essentially about the transverse direction so that the orientation ranges continuously from $\sim(012)[02 \overline{1}]$ to $(021)[01 \overline{2}]$. Neither optical microscopy nor SEM reveal any indication of transition bands. It is concluded that this orientation develops a high density of strongly misoriented zones at the subgrain level $(<10 \mu \mathrm{m})$ as will be shown by EBSP. 


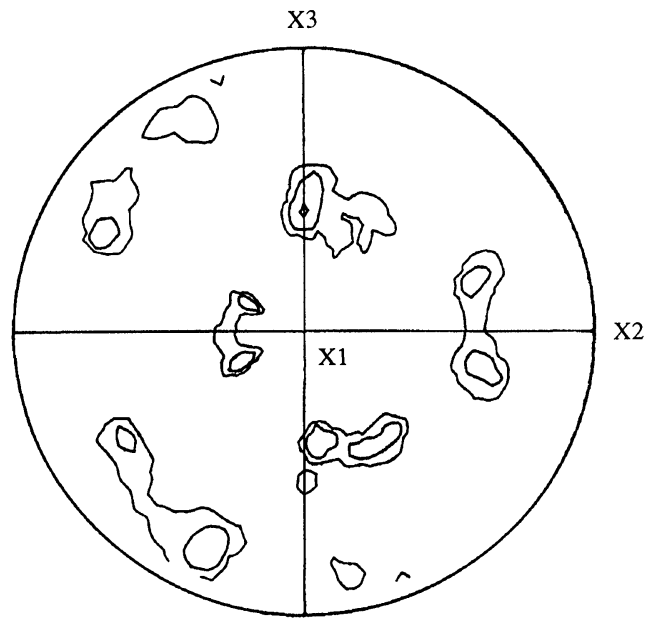

Figure $2\{110\}$ Pole figure on the transverse direction of the (001)[250] crystal at $\varepsilon=0,5$, showing pole splitting about the $X_{1}$ (=TD) direction.

\section{RECRYSTALLIZATION MECHANISMS}

Figure 4 illustrates approximate recystallization kinetics at $250^{\circ} \mathrm{C}$ for some of the orientations examined here after strains of $\sim 1$. Clearly the kinetics are quite sensitive to the crystal orientations; recrystallization occurs fastest in the orientations which contain high densities of regions with high lattice gradients, i.e. the (011)[011] and the (001)[110] crystals.

It should also be mentioned here that some preliminary recrystallization experiments have been carried out on Goss (011)[100] oriented crystals deformed to $\varepsilon=1$ and annealed at $250^{\circ} \mathrm{C}$. The Goss orientation is stable in plane strain compression and very little orientation spread occurs during deformation. On annealing recrystallization nucleation appears to be very difficult as only 1 or 2 new grains develop in the deformed samples. In this case nucleation depends on

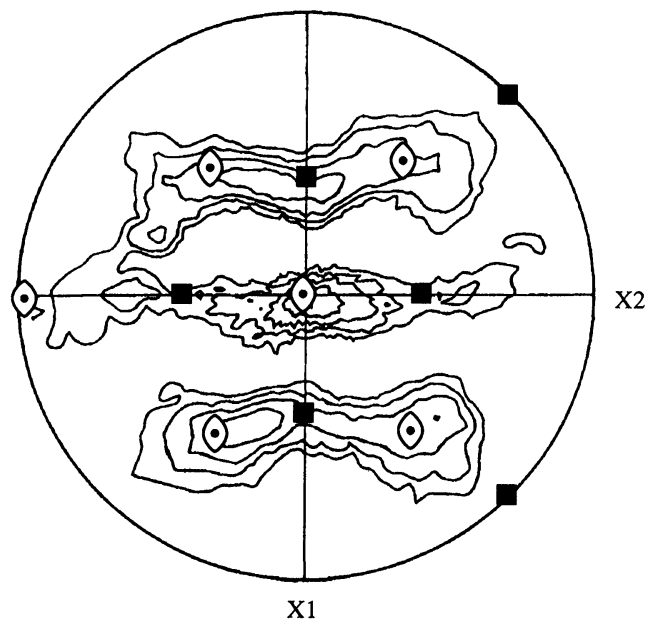

Figure $3\{110\}$ Pole figure on the compression face of the (011)[011] crystal at $\varepsilon=1$. 


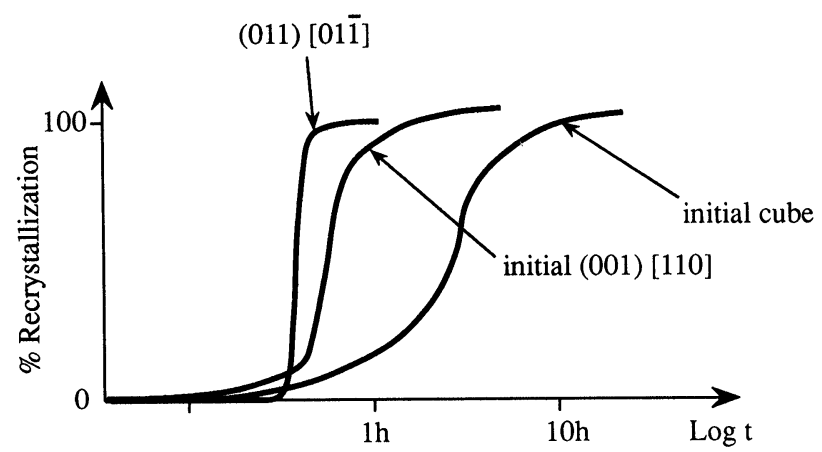

Figure 4 Approximate recrystallization kinetics of 3 crystal orientations at $250^{\circ} \mathrm{C}$ after a strain of 1.

a
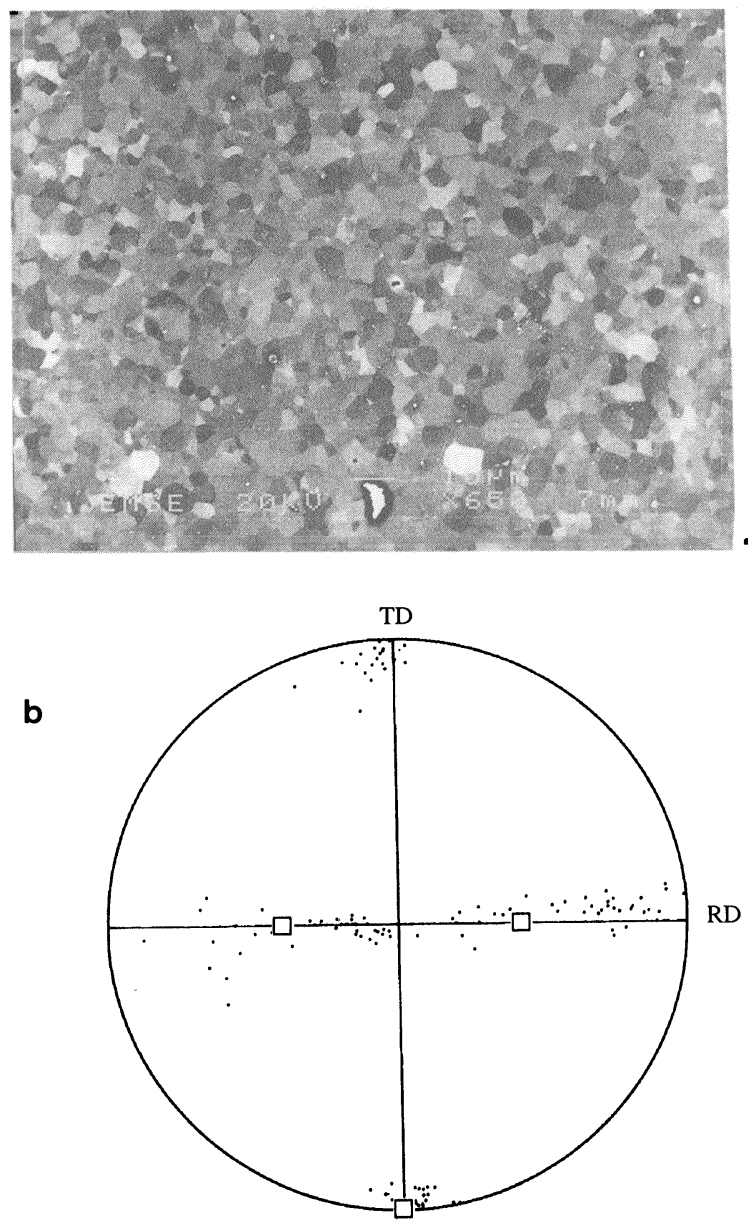

$\{100\}$ poles

$\square \quad$ Initial orientation

Figure 5 (011)[01] crystal deformed to $\varepsilon=1$ and annealed $15 \mathrm{~min}$ at $250^{\circ} \mathrm{C}$; (a) channelling contrast image of subgrain structure (compression plane), (b) $\{001\}$ pole figures of subgrain orientations determined by EBSP. 
the presence of surface defects and the kinetics are consequently very sensitive to the surface state and are therefore rather unreproducible.

\section{The (011)[011] Orientation}

The grain structures and orientations determined after the following recrystallization anneals on the orientation deformed to $\varepsilon=1$ are shown in Figures 5 to 7:

Figure $15,15 \mathrm{~min}$ at $250^{\circ} \mathrm{C}$ to an essentially well-recovered polygonized structure of relatively large subgrains $(3-6 \mu \mathrm{m})$;
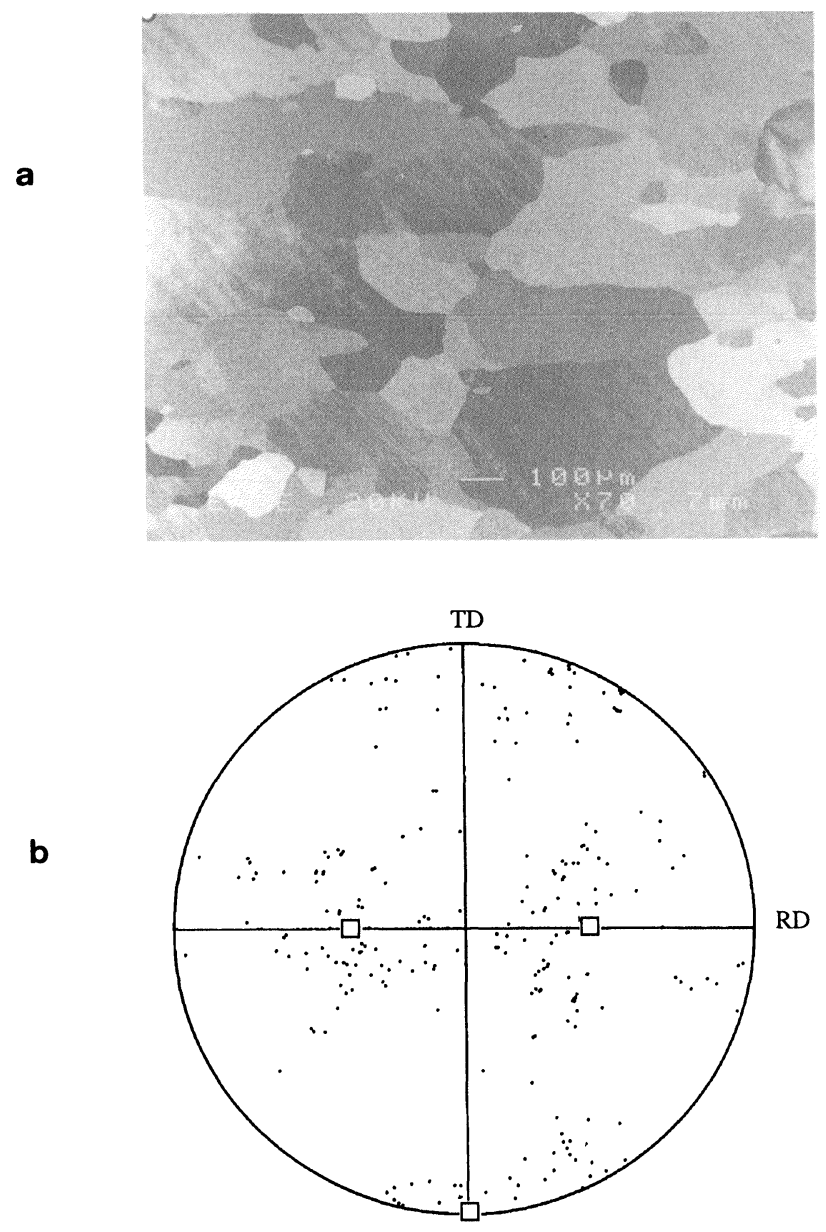

$\{100\}$ poles

$\square \quad$ Initial orientation

Figure 6 (011)[011] crystal deformed to $\varepsilon=1$, annealed $30 \mathrm{mn}$ at $250^{\circ} \mathrm{C}$ to complete recrystallization; (a) channelling contrast of recrystallized grain structure (compression plane) (b) \{001\} poles of recrystallized grains. 

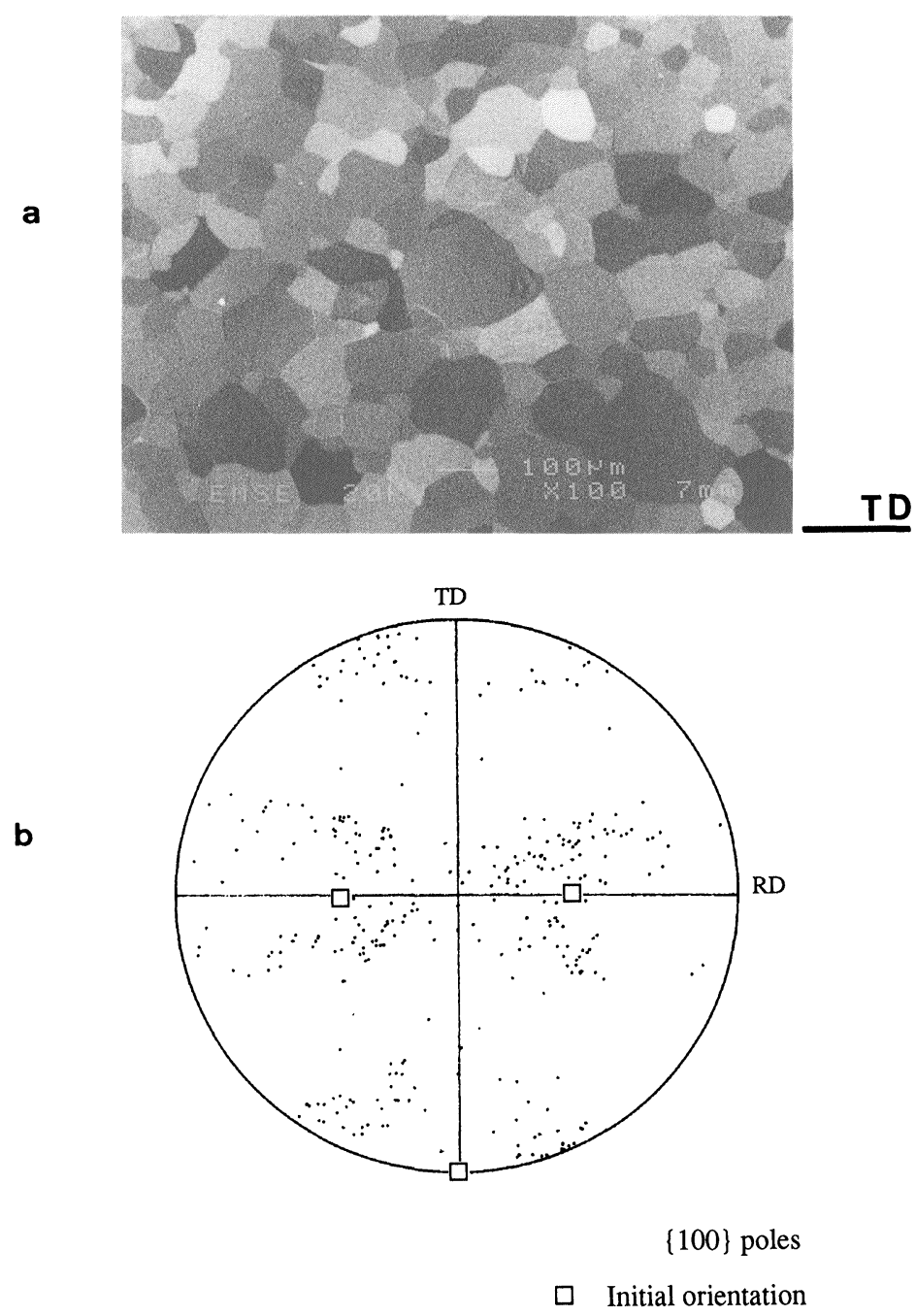

Figure $7(011)[01 \overline{1}]$ crystal deformed to $\varepsilon=1$, annealed a few seconds at $400^{\circ} \mathrm{C}$; (a) recrystallized grain structure (compression plane) (b) $\{100\}$ pole figures of recrystallized grains.

Figure $6,30 \mathrm{~min}$ at $250^{\circ} \mathrm{C}$ to a recrystallized grain structure;

Figure 7 , a few seconds at $400^{\circ} \mathrm{C}$ to a recrystallized grain structure.

The $\{100\}$ pole figures determined by EBSP on $\sim 100$ grains are shown alongside the SEM channelling contrast micrographs. The recovery stage, Figure 5 , illustrates the wide dispersion of the $\{001\}$ poles from their initial positions by rotations about TD; this is perfectly consistent with the X-ray pole figures in the the as-deformed state.

The recrystallized states (Figures 6,7 ) both show the following features:

-a relatively large spread of the recrystallized grain orientations, 
- a clear tendency for the new grains to avoid the initial crystal orientations by adopting orientations 15 to $30^{\circ}$ from the as-deformed orientation spread; this is most obvious after the $400^{\circ} \mathrm{C}$ anneal (Figure 7).

The micrographs clearly show that subgrain coarsening occurs during the early recovery stage (without a significant change in orientation distribution). Due to the very rapid recrystallization it has not yet been possible to examine partially recrystallized structures to verify the detailed nucleation mechanisms. However, the microstructural observations, together with the fact that the new grains are almost always $15-30^{\circ}$ off the set of the as-deformed orientations, strongly suggest a subgrain coalescence mechanism; subgrain coarsening occurs with increasing local misorientations until some critical misorientation (of the order of $15^{\circ}$ ) is attained and the subgrain boundary mobility is sufficient to allow extensive migration; the subgrain then becomes a recrystallization nucleus.

\section{The (001) $\langle u v 0\rangle$ Crystals}

As described above, the $(001)\langle u v 0\rangle$ crystals deformed in plane strain compression to $\varepsilon \sim 1$ contain large numbers of transition bands (TB). The highest TB density is developed in the initial (001)[110] crystals and this is reflected by their faster recrystallization kinetics.

The typical behaviour of the initial cube crystal is shown in Figure 8. Partial recrystallization at $250^{\circ} \mathrm{C}$ reveals nucleation both along the transition bands aligned in the RD direction and in the matrix adjacent to the TBs. Most grains appear in fact to recrystallize off the TBs. The orientations of the recrystallized grains exhibit a wide dispersion from the initial cube or as-deformed $\{012\}\langle 021\rangle$ orientations. A more clearly defined recrystallization texture is obtained after a short time at $400^{\circ} \mathrm{C}$, Figure 9 . In this case, where recrystallization is almost complete, a relatively well-defined cube texture develops, probably by nucleation from the TB regions (although grain growth texture effects cannot be completely ruled out).

The results available at this time concerning the cube orientation therefore appear to confirm that TBs can effectively act as cube nucleation sites, particularly at $400^{\circ} \mathrm{C}$ but that more random nucleation can also occur extensively off the TBs at lower temperatures (Akef, 1992).

The ND rotated cube orientations reveal a particularly interesting behaviour after short annealing times at $400^{\circ} \mathrm{C}$, (Figures 10,11). The new grains adopt orientations which can be classified in two groups:

(i) orientations spread around the average as-deformed matrix orientations, i.e.

TD rotated $\sim \pm 30^{\circ}$ off the initial orientations;

(ii) orientations which extend up to $\sim 30^{\circ}$ from the as-deformed matrix towards the cube orientation.

This is clearly revealed in the $\{100\}$ pole figure of the $22^{\circ} \mathrm{ND}$ rotated cube orientation, Figure 11(b), where the two sets of orientations are schematically outlined. The second set is rotated $\sim 20^{\circ}$ about [101] or [101] from the as-deformed matrix towards the cube orientations.

Note that there are virtually no recrystallized grains with the original, non-deformed orientation as would be expected from a transition band nucleation 

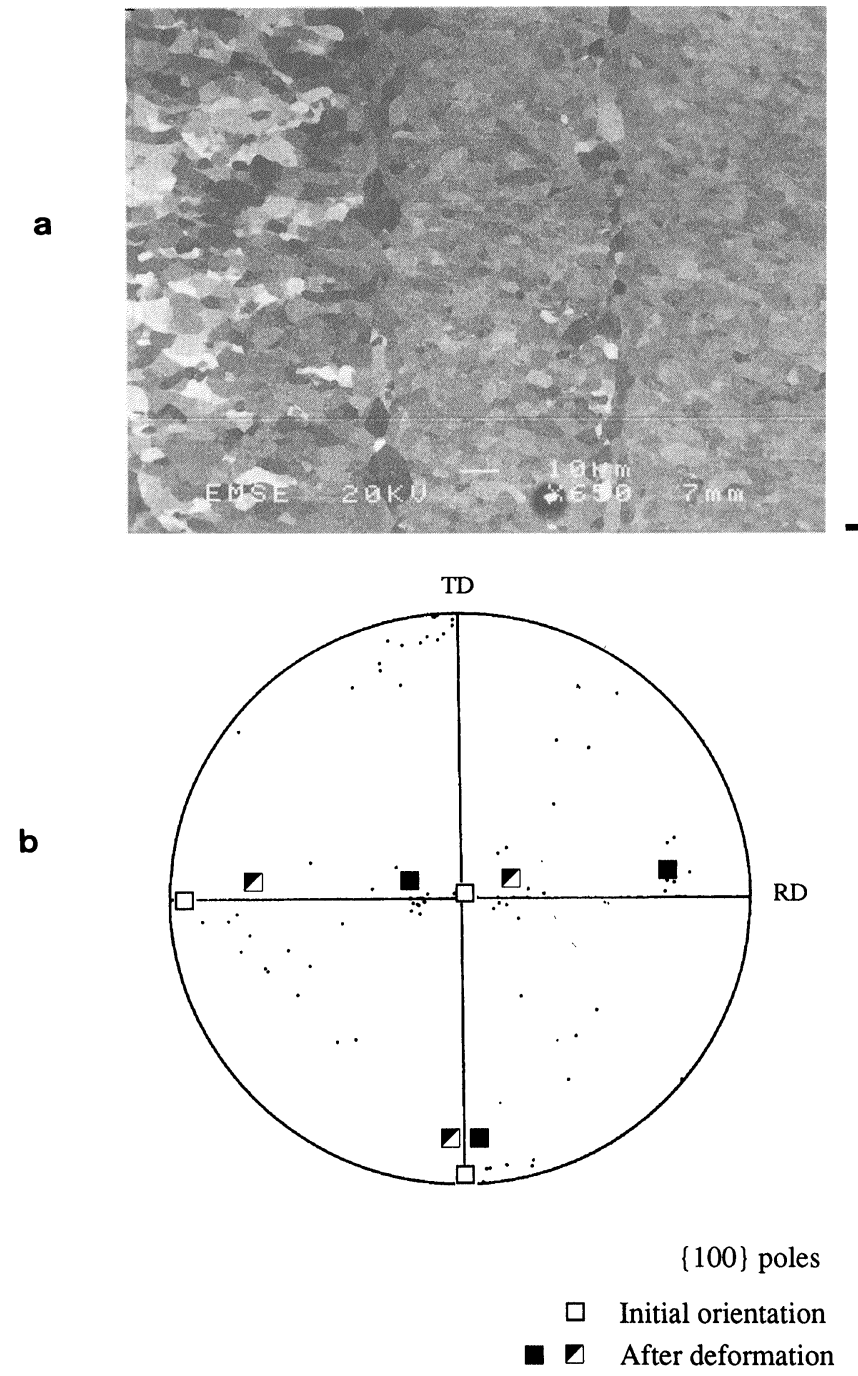

Figure 8 (001)[010] crystal deformed to $\varepsilon=1$ annealed $2 \mathrm{~h}$ at $250^{\circ} \mathrm{C}$; (a) Recrystallization nucleation along TBs and in the matrix (compression plane) (b) $\{100\}$ poles of recrystallized grains from (a).

mechanism (the transition bands should have the initial crystal orientations as a consequence of the symmetrical rotations of the adjacent bands). This would tend to rule out the possibility of a nucleation mechanism directly from the TBs. A similar absence of nucleation directly from the TBs has been observed in a deformed (001)[110] crystal by Butler, Blicharski and Hu (1991). In fact the orientation distributions of the recrystallized grains correspond more to subgrain coalescence as the controlling mechanism. In particular, the set of orientations rotated towards the cube orientation implies some directional coalescence mechanism, i.e. a dislocation substructure such that the dislocation rearrangement process during coalescence favours lattice rotations towards (001)[010]. 
a

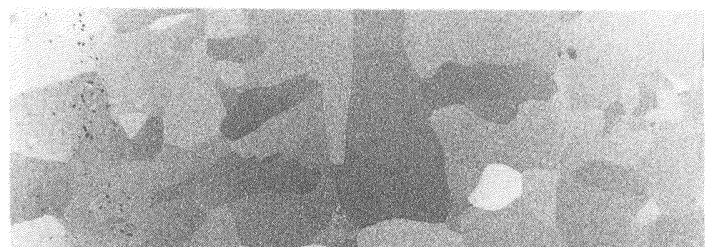

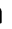

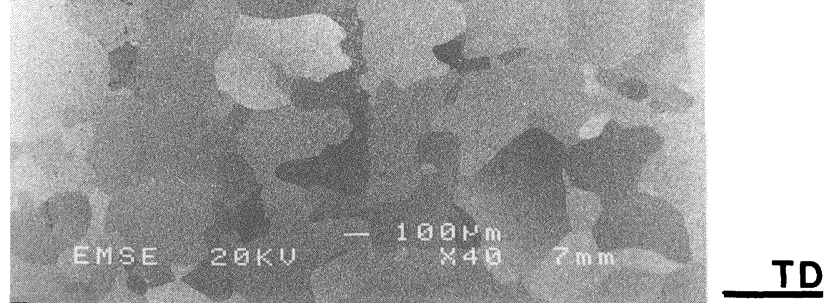

b

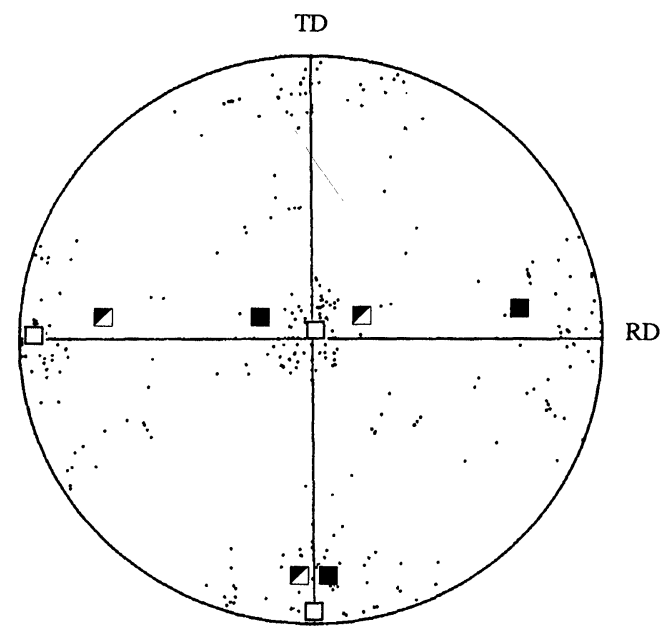

$\{100\}$ poles

$\square \quad$ Initial orientation

- After deformation

Figure 9 (001)[010] crystal deformed to $\varepsilon=1$, annealed a few seconds at $400^{\circ} \mathrm{C}$; (a) Recrystallized grain structure (compression plane) (b) $\{100\}$ poles of grains from (a).

\section{DISCUSSION AND CONCLUSIONS}

Single crystals of high purity aluminium have been deformed in plane strain compression to strains of the order 1 to develop different types of deformation heterogeneities:

(i) a uniformly distributed strongly misoriented subgrain microstructure with a fibre-texture, in the (011)[011] crystal. 

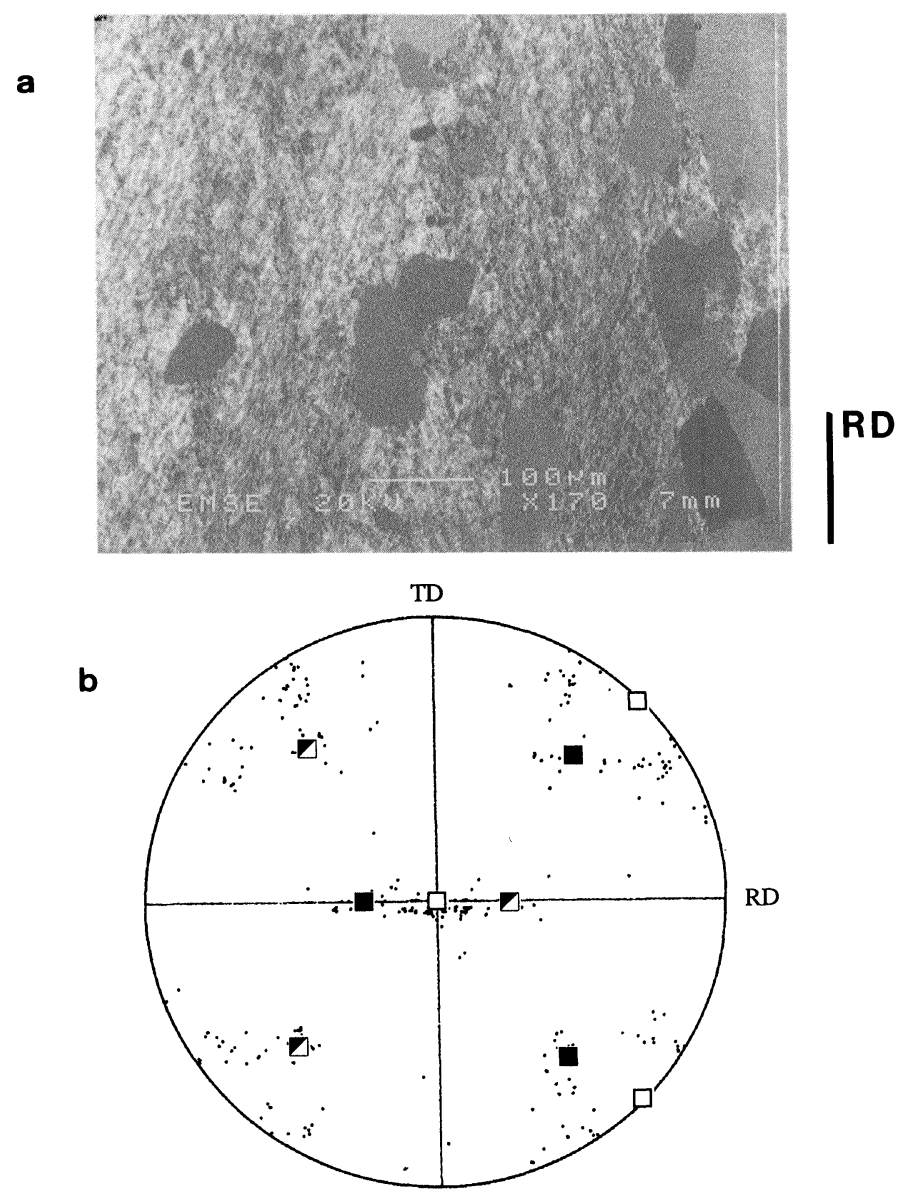

$\{100\}$ poles

$\square \quad$ Initial orientation

- $\square$ After deformation

Figure 10 (001)[110] crystal deformed to $\varepsilon=1$, annealed a few second at $400^{\circ} \mathrm{C}$; (a) partially recrystallized grain structure (transverse plane section) (b) $\{100\}$ poles of recrystallized grains.

(ii) a low density of transition bands aligned in the RD/TD plane in the initial cube crystal decomposed to $\{012\}\langle 021\rangle$.

(iii) a high density of transition bands in the RD/TD plane of the initial (001)[110] crystal after decomposition to $\{112\}\langle 111\rangle$ components.

(iv) transition bands aligned in the RD/ND and RD/TD planes in the intermediate crystal orientation (001)[250].

The recrystallization behaviour at 250 and $400^{\circ} \mathrm{C}$ of these deformed crystals has been followed by microtexture techniques (EBSP in a SEM) and correlated with the macro textures from $\mathrm{X}$-ray pole figures. 
a
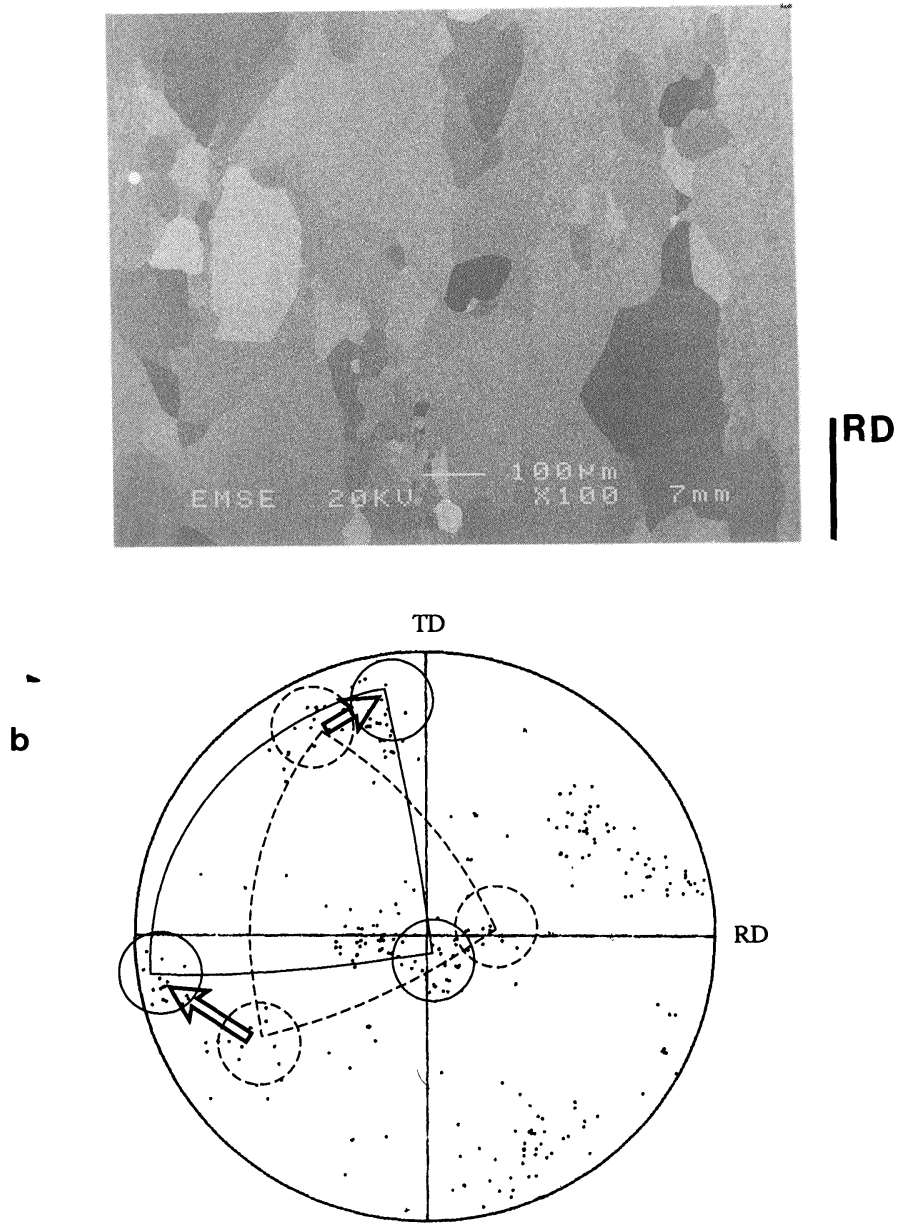

$\{100\}$ poles

Figure 11 (001)[250] crystal deformed to $\varepsilon=1$, annealed a few seconds at $400^{\circ} \mathrm{C}$; (a) Recrystallized grain structure (transverse plane section) (b) $\{100\}$ poles of recrystallized grains.

Recrystallization nucleation takes place both in the deformed matrix and along transition bands. It has not yet been possible to specify the exact detailed mechanisms for each crystal orientation; nevertheless the results obtained so far lead to the following tentative conclusions:

(1) In virtually all cases a significant fraction of the grains appear to nucleate by a subgrain coalescence mechanism. This is consistent with the observed nucleation sites-within the deformed matrix-and their orientations. The latter are often 15 to $30^{\circ}$ off the average deformation matrix orientations in agreement with the requirement of a minimum $15^{\circ}$ misorientation for boundary mobility. The subgrain coalescence mechanism occurs exclusively in the 

$250^{\circ} \mathrm{C}$

$(011)[01 \overline{1}]$ crystal and extensively in the $(001)\langle u v 0\rangle$ crystals, particularly at

(2) Nucleation also appears to take place along transition bands particularly in the initial cube orientation. The TB orientations should be intermediate between the symmetrically rotated adjacent deformation bands on either side, i.e. close to the original orientations. In fact very few recrystallized grains have the original orientations (see for example Figure 11), the significant exception being the cube crystal recrystallized at $400^{\circ} \mathrm{C}$. This implies that nucleation on or close to transition bands leads to recrystallization orientations off those of the symmetric TB.

There appears to be a significant influence of the temperature on the orientation distributions of the recrystallized grains. At $250^{\circ} \mathrm{C}$ the grains tend to be oriented around the as-deformed matrix orientations in accordance with the subgrain coalescence model. At $400^{\circ} \mathrm{C}$ there is a greater tendancy for orientations to develop close to those expected of the transition bands. This difference can be attributed to the higher degree of recovery that occurs after relatively long periods $\left(\sim 10^{3} \mathrm{sec}\right)$ at $250^{\circ} \mathrm{C}$ than after $\sim 3$ or 4 secs at $400^{\circ} \mathrm{C}$. Furu, Marthinsen and Nes (1992) have reported hardness measurements on cold rolled and annealed aluminium which show that recovery softening at $275^{\circ} \mathrm{C}$ is of the order of $60 \%$ of total softening compared with $\sim 25 \%$ after a few secs at $375^{\circ} \mathrm{C}$. The extensive recovery at $250^{\circ} \mathrm{C}$ therefore allows the subgrains to coalesce whereas at $400^{\circ} \mathrm{C}$ the transition bands become more active nucleation sites. This would imply a higher activation energy for nucleation from transition bands than by subgrain coalescence. This needs to be confirmed by further work to specify in detail the orientations of the transition bands and their role in recrystallization nucleation.

These preliminary results will be followed up, in particular by recrystallization experiments on crystals deformed to higher strains (of the order of 2 or 3) corresponding to narrower transition bands with higher orientation gradients located between relatively stable orientations.

\section{References}

Akef, A. (1992). Doctoral Thesis, Ecole des Mines de St-Etienne.

Akef, A. and Driver, J. H. (1991). Mater. Sci. Eng., A132, 245-255.

Becker, R., Butler, J. F., Hu, H. and Lalli, L. A. (1991). Metall. Trans., 22A, 45-58.

Butler, J. F., Blicharski, M. and Hu, H. (1991). Textures and Microstructures, 14-18, 611-616.

Dillamore, I. L. and Katoh, H. (1974). Metal Sci., 8, 73-83.

Doherty, R. D., Gottstein, G., Hirsch, J., Hutchinson, W. B., Lucke, K., Nes, E. and Wilbrandt, P. J. (1988). In Proceedings ICOTOM 8, 563-572.

Furu, T., Marthinsen, K. and Nes, E. To be published.

Hjelen, J., Orsund, R. and Nes, E. (1991). Acta Metall. Mater., 39, 1377-1404.

Orlans-Joliet, B., Driver, J. H. and Montheillet, F. (1990). Acta Metall. Mater. 38, 581-594.

Schmidt, N. and Olesen, N. O. (1989). Canad. Mineral, 27, 15-22.

Skalli, A. (1984). Doctoral Thesis, Grenoble. 